\title{
LO PRIVADO. APRENDIZAJES TÁCITOS
}

\author{
Privacy. Tacit learning
}

\section{Teófilo RODRÍGUEZ NEIRA}

Universidad de Oviedo. Departamento de Ciencias de la Educación.

Facultad de Ciencias de la Educación. C/. Aniceto Sela, s/n. 33005 Oviedo.

Fecha de aceptación definitiva: marzo de 2000.

BIBLID [(1130-3743) 11, 1999, 85-100]

RESUMEN

Se analizan algunos de los espacios y lugares en los que transcurre la vida humana. Se presta especial atención a lo privado e íntimo. Aquí se llevan a cabo conductas que sólo en ellos pueden realizarse. Facilitan aprendizajes que, al no ser, con frecuencia, intencionales ni deliberadamente propuestos, son considerados como tácitos e implícitos, constituyendo una parte esencial de la personalidad.

SUMMARY

We analyze some spaces and places where human life develops. We pay special attention to privacy and intimacy where some behaviours, that only there can be carried out, take place. They provide learnings, which being neither deliberately proposed nor intentional, must be considered as tacit and implicit. They are an esential part of the personality.

"La mayor parte de la vida de los seres humanos transcurre en las casas. Alli se procrea, se amamanta, se dan los primeros traspiés, se aprende a bablar, se juega, se come, se ama, se duerme y se descansa. Sobre todo: en las casas se sueña". [ECHEVERRÍA: 1995, 46]. 


\section{INTRODUCCIÓN}

Constatamos con facilidad modificaciones y cambios de nuestra conducta, algunos de ellos de limitada duración y de ligerísimo peso, que se producen a medida que se transforman las situaciones en las que nos encontramos y los medios por los que discurrimos. Las relaciones personales y los ámbitos espaciales son condiciones que introducen, con su mera presencia, componentes vivenciales capaces de afectar las aguas de nuestro equilibrio personal. Pasear por los escondidos caminos solitarios de un bosque facilita sensaciones que desaparecen cuando uno se encuentra circulando por las calles multitudinarias de una gran ciudad. No es emocionalmente lo mismo encontrarse con personas a las que nos unen lazos afectivos que participar profesionalmente en un cometido técnico. Los hogares, los espacios privados, y las relaciones íntimas, familiares, facilitan comportamientos que sólo ahí pueden fructificar provechosamente, o malograrse trágicamente. En realidad, estos espacios y estas relaciones son los semilleros de la estimativa humana. Ahí se consolidan, o se destruyen las representaciones primeras de lo que se considera como justo o injusto, de lo que se percibe como bueno o malo. Los cimientos de los criterios axiológicos sólo fraguan y adquieren consistencia en esas situaciones. La sospecha fundada que inmediatamente nos asalta es que los educadores morales no podrán llevar a cabo su tarea si no tienen en cuenta las circunstancias emocionales en las que la vida se abre al mundo, si no las analizan y son capaces de captarlas en toda su nitidez. La propuesta sigue un camino que corrige, en parte, los esquemas de Piaget y Kohlberg. ¿Cómo y dónde nacen las primeras representaciones axiológicas, las actitudes éticas, no las simplemente morales y jurídicas?. ¿De qué características se revisten las relaciones y los espacios que las hacen posibles?

\section{LO PRIVADO Y LO PÚBLICO}

Los creadores de la Antropología urbana han perfilado los rasgos y características del hombre público actual. Pertenece a una configuración que desborda las viejas dicotomías y sobrepasa los antiguos regímenes en los que se consideraba perfectamente definido. Lo público es ahora más que lo simplemente presente a los demás y se muestra a la observación ajena. "El espacio público, describía Delgado, tiende a constituirse en escenario de un tipo insólito de estructuración social, organizada en torno al anonimato y la desatención mutua o bien a partir de relaciones efímeras basadas en la apariencia, la percepción inmediata y relaciones altamente codificadas y en gran medida fundadas en el simulacro y el disimulo... De la vivencia de lo público se derivan sociedades instantáneas, muchas veces casi microscópicas, que se producen entre desconocidos en relaciones transitorias y que se construyen a partir de pautas dramatúrgicas o comediográficas -es decir, basadas en una cierta teatralidad-, que resultan al mismo tiempo ritualizadas e impredecibles, protocolarias y espontáneas...” (Delgado, 1999, págs. 12-13). 
Todos los habitantes urbanos transitan por los espacios públicos, por las calles, las plazas, las estaciones, los aeropuertos, aliviados del peso de la constante identificación, de la fuerte personalización privada. Forman el río de los transeúntes que van de un sitio para otro, que se desplazan y se interpretan bajo las formas que siempre, tal vez, han querido ser y que nunca han llegado a satisfacer completamente. Seductores y seducidos, conquistadores y conquistados, altivos, soberbios o humildes, se hacen como son capaces de afirmarse y expresarse sin necesidad de que eso llegue a permanecer definitivamente y en todo momento bajo la misma forma y bajo modos de ser idénticos.

Llega, sin embargo, un momento del día, o de la noche, en el que la marea humana retrocede, se oculta en lugares escondidos, cerrados. La calle, la plaza, el trabajo, ceden su carga a los hogares, a las viviendas, a otros grupos y a otras relaciones. Nada de lo que valía y se cotizaba, de lo que se exhibía en el espacio público, sirve para los dominios domésticos. Aquí existe otro mundo, otra vida. Los criterios y las reglas cambian. Nada significa lo que significaba. Más bien son formas y tipos contrarios. Vida pública y vida privada se niegan entre sí. No siempre ha sido así. Pero, actualmente, esas dos esferas evolucionan, entre conflictos y tensiones, divergentemente.

"La problemática social de la gran ciudad moderna no radica tanto, en el presente momento, en la urbanización total de la vida, cuanto en la pérdida de características esenciales de la vida urbana. La interrelación entre esfera pública y esfera privada ha sido destruida, pero no porque el hombre de la gran ciudad sea un hombre-masa, sino porque ya no le es posible contemplar la cada vez más complicada vida global de la ciudad de un modo que le resulte público. Cuanto más la globalidad de la ciudad se convierte en una jungla difícilmente penetrable, más se recluye él en su esfera privada -cada vez más ampliada-, acabando, no obstante, por percibir que no es motivo menor de la disgregación de la publicidad urbana la conversión del espacio público en mal organizada superficie de un tráfico tiránico" (Ref. Habermas: 1981, 188).

La vida urbana trepidante, "escaparatizada", inmensa, anónima, devuelve al individuo hacia recintos donde le sea posible encontrarse con los suyos y con lo suyo, donde resguardar algo único y propio. Convierte en necesaria una dimensión distinta de la vida. Y, en este instante, acucia la necesidad de tornar sobre esa dimensión y reanalizar las características ideales que le corresponden. Es decir, urge tomar de nuevo las comunidades inmediatas, los grupos primarios y los domicilios para ver las propiedades que los definen y las respuestas que desde ellos se pueden ofrecer a la existencia. Una intervención educativa sensata pasa por la comprensión de estos ámbitos. Porque las estrategias que se organicen sólo tendrán sentido después de conocer dónde tendrán que desarrollarse y para qué se llevan a cabo. 


\section{COMUNIDAD}

El ser humano, desde el mismo momento de su nacimiento, está sometido a un sistema de relaciones que intervienen directamente en su vida y que, inevitablemente, formarán parte de su experiencia y forjarán, en gran medida, el equipamiento psíquico con el que tendrá que abordar su existencia. Sus ojos se abren al mundo en el seno de una "comunidad" que lo acoge, desvalido e inerme, y a través de ella dará sus primeros pasos en la vida. La "comunidad" es la puerta de salida al universo. Es también su primer apoyo, su primer soporte y su primera referencia.

"La historia de la vida del individuo -escribió Ruth Benedict- es ante todo y sobre todo una acomodación a las normas y pautas tradicionalmente transmitidas en su comunidad. Desde el momento del nacimiento, las costumbres en medio de las cuales ha nacido modelan su experiencia y su conducta. Desde el momento en que puede hablar, es la pequeña criatura de la cultura, y cuando ha crecido y se ha hecho capaz de participar en actividades de ella, sus hábitos son los de ella; sus creencias, las creencias de ella, y lo mismo ocurre con sus limitaciones. Todo niño nacido en su grupo participará con él de ellas, y ninguno de sus antípodas lo logrará jamás, ni siquiera en la milésima parte. No hay problema social cuya comprensión no importe más que el del papel de la costumbre. Hasta que entendamos sus leyes y variedades, permanecerán ininteligibles los principales hechos complejos de la vida humanan (Benedict: 1971, 15).

Al hablar de la "comunidad", de comunidades sociales en cuanto reducto en los que la vida humana se despierta, estamos hablando de hábitos, costumbres, modos de actuar, pautas, modelos, tradiciones y cultura. Es decir, la "comunidad" es el lugar de la convivencia y es el medio de circulación de los instrumentos iniciales de la posición del hombre ante el mundo y de su interpretación.

Pero la palabra "comunidad" es un término de usos múltiples. Con ella nos referimos a la "comunidad familiar", a la "comunidad grupal", a la "comunidad institucional. Y también indicamos con ella alianzas de gran extensión y amplitud: la "Comunidad del Atlántico Norte" o la "Comunidad Económica Europea". Incluso nos referimos con ella a relaciones basadas en la raza o la religión, como cuando hablamos de las "comunidades de negros en Estados Unidos" o de las "comunidades étnicas» en distintos países y pueblos. Es preciso, entonces, delimitar el concepto de comunidad y ver después sus efectos educativos.

\section{NATURALEZA DE LA "COMUNIDAD” Y DE LAS ORGANIZACIONES COMUNITARIAS}

El concepto de "comunidad" como categoría social y "tipo ideal" de relación humana ha sido incorporado a la Sociología por Ferdinand Tönnies. Antes fue usado por Kant, quien llamaba "comunidad de acción recíproca" a una de las categorías de la relación, definiendo la "comunidad" como "reciprocidad de acción entre el agente y el paciente". Sin embargo, como decimos, se debe a Tönnies su 
definitiva elaboración sociológica y su aplicación a la hora de explicar las relaciones interpersonales.

La "comunidad" (Gemeinschaft) aparece contrapuesta a la "sociedad" (Gesellschaft), caracterizada y diferenciada frente a lo social.

Las voluntades de los hombres, argumentaba Tönnies, establecen entre sí múltiples y diversas relaciones. Cada una de estas relaciones expresa una acción mutua, pues una interviene como activa y dadora, mientras la otra es pasiva o receptora. Las acciones que unos hombres ejercen sobre los otros tienden a la conservación o a la destrucción de las voluntades u organismos diferentes. Es decir, estas acciones son positivas o negativas. Sólo las relaciones positivas son las que darán lugar a la "comunidad" o a la "sociedad". Y se llaman positivas porque mediante estas acciones se consiguen "relaciones de afirmación reciproca". Constituyen, por tanto, una "unidad" en la que se integra lo que es "plural" y distinto. El grupo formado por las relaciones positivas constituye un «ligamen (Verbindung) que actúa como unidad tanto hacia el interior como hacia el exterior.

Las acciones recíprocas, las relaciones de que habla Tönnies, son, en último término, de índole psicológica, ya que son expresiones de formas de querer y desear humano. Consisten en estímulos, prestaciones, servicios que las partes intercambian entre sí y que se consideran expresión de las diversas voluntades y las fuerzas respectivas". (Tönnies: 1977, 827 y ss.).

Por una parte, existe un querer y un desear humano de índole natural, orgánica, que remite hasta la vida vegetativa misma. Por otra, hay una voluntad de elección, «una voluntad fáctica y reflexiva”. El querer orgánico, natural, lleva en sí las condiciones de la "comunidad". La voluntad "reflexiva" produce la sociedad. En el orden de la comunidad, el todo relacional existe antes que las partes. Del mismo modo, el pensamiento forma un todo orgánico y real con el querer natural por el que está rodeado. En la sociedad, por el contrario, «el todo social no es más que un compuesto de las partes". En el mismo sentido, la voluntad reflexiva constituye la unidad mental como algo artificial o ideal que contiene la voluntad misma.

Las formas embrionarias de la comunidad se dan en la "comunidad de sangre». Son la relación materna, la relación sexual y la relación fraternal. También se extienden y desarrollan hasta "la comunidad de lugar.

Las tres relaciones comunitarias esenciales son la relación de parentesco, la relación de vecindad y la relación de amistad.

Al contrario que en la comunidad, el acto societario típico es el del intercambio. "Se lleva a cabo entre individuos extraños por la sangre que, en consecuencia, pueden ser considerados como enemigos naturales..

De un modo más general, se puede decir que a la comunidad pertenece "todo lo que es confiable, intimo, que vive solo en conjuntom. La sociedad está formada por lo que es público, extraño. Constituye "el mundo». El individuo se encuentra en comunidad con los suyos desde el nacimiento, ligado a ellos tanto en lo bueno como en lo malo. Se penetra en la sociedad, sin embargo, como en "tierra extranjera". La familia es la expresión "general de la realidad comunitaria". La sociedad 
comercial lo es del "orden societario". Con la sociedad nos movemos en el reino de la razón calculadora, la abstracción y las relaciones mecánicas"... Comunidades y sociedad están presentadas aquí como "tipos ideales", como conceptos normativos y categorías. Parcialmente, por lo tanto, son inadecuadas a la realidad, pero expresan la dirección en la que la realidad se define.

El tema de la comunidad y de las relaciones comunitarias ha entrado a formar parte necesaria, después de Tönnies, de las consideraciones sobre los sistemas de interacción del ser humano. Precisamente por ello, no siempre se le han atribuido las mismas características funcionales y estructurales. Hans Freyer, por ejemplo, piensa que la concepción de Tönnies está condicionada y limitada por un excesivo psicologicismo. El recurso a la voluntad y a las formas de desear significa hacer un planteamiento basado en elementos psíquicos, olvidando los aspectos estructurales. Y, teniendo éstos en cuenta, Hans Freyer piensa que lo que realmente define a la comunidad es la ausencia de dominación "en el seno del grupo en convivencia. Es decir, que por distinta y diferenciada que sea la forma en la que se organiza la convivencia comunitaria, no hay en ella, sin embargo, "ningún grupo parcial cuya relación con los demás grupos parciales sea una relación de dominación. En sentido positivo ello quiere decir que, en principio, el patrimonio cultural del grupo en cuestión, lo mismo el material que el espiritual, existe intacto y total como propiedad en cada uno de los miembros del grupo. La ley estructural de la comunidad no se encuentra plenamente realizada más que alli donde un mundo cerrado de contenido espiritual característico es poseido en común por todo un grupo (Freyer: 1973, 145).

Si tratamos de reunir bajo un esquema general las propiedades que mejor representan las formas de convivencia que merecen el nombre de comunidad, al menos, tenemos que mencionar las siguientes:

a) Las relaciones de comunidad son siempre relaciones personales estrechas, relaciones de unas personas con otras personas, de tú a tú. A esas relaciones se las denomina relaciones primarias, y comprenden las dimensiones más íntimas de los sujetos singulares.

b) Los individuos están unidos por lazos emotivos y afectivos tanto entre sí como ante el conjunto de las funciones de grupo.

c) Todos los miembros se encuentran bajo un mismo compromiso ante los valores que se consideran significativos y representativos del grupo. La cohesión nace de una entrega y sensación de mutua pertenencia.

d) Los individuos están relacionados entre sí bajo un sentido de solidaridad previo a las decisiones singulares y a las situaciones en que se encuentren.

Los antropólogos y sociólogos admiten, con frecuencia, que la vida de comunidad se da en estado puro en colectividades reducidas y primitivas. La sociedad moderna, evolucionada, industrializada, ha ido desplazando esta forma de organización social hasta convertirla en un ideal más que en la expresión de una realidad concreta. La gran urbe, la multiplicidad compleja de las ofertas de relación, de 
dominio del orden público, como señaló Habermas, sobre el privado y personal, han invadido la vida de comunidad hasta casi eliminarla en aras de un orden global de lo social. Subsiste únicamente retraída sobre sí misma y bajo permanentes amenazas de desaparición.

La situación de la comunidad y de las formas en que se realiza tiene una profunda repercusión en la escuela, porque afecta a la estructura de la personalidad de los seres humanos. Las demandas educativas de la sociedad se pueden encontrar sin respuesta por parte de los sujetos singulares al encontrarse éstos desposeídos del medio y ámbito en el que fructifican sus más profundos intereses. El problema se puede ver más directamente si nos detenemos en las funciones de las "comunidades inmediatas", de los "grupos primarios", de la familia, de las relaciones de vecindad y amistad.

\section{GRUPOS, FAMILIAS}

Ya hemos señalado que la forma más perfecta de la comunidad es la familia. Pero las relaciones de comunidad, las relaciones familiares, la escuela misma, han sido analizadas en términos de grupos y de formaciones grupales. La incorporación de las categorías grupales para describir las relaciones interpersonales ha tenido una gran repercusión en la concepción del proceso educativo, en la determinación de las demandas de enseñanza y en la organización práctica de la educación. En realidad, podemos decir que, a partir de mediados de nuestro siglo y durante algunas décadas, el problema de los grupos humanos fue, desde una cierta perspectiva, el problema de la dinámica de la personalidad y el problema de la dinámica del aprendizaje.

El pensamiento sociológico y la interpretación de las relaciones humanas dispuso durante mucho tiempo de dos conceptos básicos para describir la realidad social: individuo y sociedad. El grupo no había sido, ni tal vez podía ser, pensado como una entidad específica. A lo sumo, se concebía como individualidades multiplicadas con un número más o menos grande. Cuando Platón analiza en el libro VII de la República la educación y las características que deben tener los dirigentes de la ciudad, no habla de ellos como "clases" ni como grupo, sino como elementos que se integran en la sociedad y que reciben de ésta el sentido y función que les corresponde. Es durante el siglo XIX cuando, coincidiendo con la Revolución Industrial y con el inicio de la expansión urbana, comienza a surgir la comprensión de la naturaleza de los grupos sociales. Porque aparece "una inmensa variedad de formaciones" y porque "cada una de ellas produce un impacto diferente sobre la conducta individual.

Comte, Marx, Spencer, precedidos de algunos novelistas de siglos anteriores que muestran una gran sensibilidad para captar y enfrentar los rasgos distintivos de los comportamientos convencionales, se plantean sistemáticamente los problemas de la "aparición de los grupos dentro de la sociedad". A partir de aquí se ha podido 
ir observando que los niños y los adultos se comportan de distinta manera, matizan o alteran profundamente su conducta, según el grupo en el que se encuentran. Familia, amigos, escuela, hogar, oficina o fábrica son lugares donde cambian muchas formas y actitudes. Una misma persona puede ofrecer la imagen de individualidades perfectamente separables y hasta contrarias. "Es siempre la variable naturaleza de esas organizaciones la que atrae formas apropiadas de conducta" (Mannheim: 1966, 184).

Una de las clasificaciones de los grupos comúnmente aceptada y que mejor expresa los rasgos atribuidos por Tönnies a la comunidad y a la sociedad es la que los divide en grupos primarios y grupos secundarios. El prototipo del grupo primario es la familia, la forma familiar de la comunidad. En estos grupos, como afirmábamos de la comunidad, se lleva a cabo la vida "más intima, espontánea y variada. Se ha llamado a estos grupos primarios la "nursery" de la naturaleza humana. En su seno despierta el hombre al mundo y a la vida. Las primeras experiencias agradables o dolorosas, los primeros sentimientos, brotan, crecen o se agostan en el marco de la comunidad inmediata, en el marco familiar. Y estos hechos condicionarán el futuro. En este ámbito, las relaciones individuales prevalecen sobre los aspectos formales y funcionales.

Los grupos secundarios, sin embargo, se caracterizan porque los miembros "se ponen únicamente en contacto directo uno con otro por medio de una relación formal (como es el caso de los delegados de una conferencia) o por medio de informes o comentarios o por cualquier otro contacto indirecto. La característica de la agrupación secundaria es que es difícil para las personas implicadas el establecer cualquier contacto real uno con otro y tienen que contentarse con una relación funcional y fragmentaria. Las organizaciones de gran escala, ya sean industriales, educativas o políticas, pueden ofrecer relaciones principalmente de este tipo de grupos secundario" (Mannheim: 1966, 184).

El soporte grupal es importante para descifrar el comportamiento y la conducta humana, para entender las funciones educativas que desempeñan. Aun admitiendo que solamente el individuo constituye la última unidad de la acción social, que es "fundamento de la realidad" y que la naturaleza de los grupos es derivada, continúa siendo cierto que para comprender su conducta y las influencias que recibe es necesario conocer antes las constelaciones y organizaciones en las que actúa.

\section{DISTINTAS FORMAS DE COMUNIDAD Y DE ORGANIZACIÓN SOCIAL}

No todas las "formaciones" ejercen la misma influencia y tienen el mismo impacto educativo. Las actitudes primarias de simpatía, "amor, resentimiento, ambición, vanidad, heroísmo, valor, sentido de justicia social o del bien y del mal en general, amabilidad, bonestidad, deferencia por la opinión pública, temor al ridiculo, éstas y muchas otras actitudes primarias tienen sus raíces en nuestra pri- 
mera experiencia y pueden encontrarse de formas diferentes en cada sociedad, no porque necesariamente sean instintos innatos, sino porque todas las sociedades tienen grupos primarios (formas de comunidad inmediata), especialmente el de la familia, y en tales grupos las cualidades que be mencionado anteriormente se desarrollan de forma espontánea, porque sin ellas las personas no podrian vivir juntas en ningún grado de amistad o felicidad. No es por puro accidente por lo que casi todos los códigos de las religiones contienen virtudes primarias" (Mannheim: 1966, 185-186).

A medida que el individuo participa en grupos más amplios, las experiencias personales se extienden más allá de la familia y se comienza a construir respuestas generalizadas en forma de principios morales o ideales abstractos. De esta manera, "las generalizaciones que parecen gobernar la vida de las organizaciones sociales superiores, se desarrollan muy gradualmente de actitudes e imágenes primarias a medida que aquéllas se propagan y se hacen más elaboradas".

Como puede observarse, dado el planteamiento que venimos desarrollando, el núcleo, el punto de partida y la materia sobre la que se teje la urdimbre de la vida nace y fructifica en los grupos primarios. Naturalmente, también allí puede malograrse. No todas las actitudes son positivas. En los grupos primarios, en lo que hemos denominado formas de comunidad inmediata, aparecen con frecuencia la distorsión, el engaño, la injusticia, la insolidaridad, la malevolencia y la destrucción. Corregir lo negativo y acentuar las cualidades que favorecen la convivencia, la justicia, el bien común, es educar. Cuando el niño llega a la escuela, por muy temprana que sea su participación en ella, está ya equipado o va dotado con dispositivos humanos poderosos que afectan gravemente a su posición en la escuela y en el resto de las organizaciones. Es a partir de estos engranajes cómo la institución escolar debe iniciar el desarrollo de su tarea. Sus alumnos no son una tierra virgen que hay que roturar. Son ya un mundo complejo surcado de múltiples experiencias que es necesario potenciar o corregir.

\section{FAMILIA, ESCUELA, GRUPOS SOCIALES}

En el conjunto del discurrir humano, cada institución, cada forma organizativa, cada estructura de la convivencia, ya se trate de la familia, de la escuela o del estado, asume y desempeña dentro del proceso educativo un papel y una función que, de antemano, debe estar definida y delimitada. Ya sabemos que la civilización, la cultura, los patrones, normas, reglas, prescripciones, modelos, las formas que rigen la vida de los grupos, de la comunidad, de la sociedad, constituyen un tupido sistema por el que circula la existencia de cada uno de los individuos concretos. La singularidad y autonomía, la independencia y el "sí mismo" propio, no se consiguen nunca si no es a través de la paulatina comprensión y especificación de los elementos que nos integran. Incluso se puede establecer que la manera más fácil de influir en el hombre es mediante sus vínculos sociales. De este modo, la familia, los grupos, ejercen su contribución, intervienen como agencias educadoras desde 
dos dimensiones. Una de ellas es de carácter indirecto, automático, espontáneo y constante. El hecho de encontrarse en una familia concreta, parental amplia, nuclear, conyugal, bipersonal o pluripersonal, organizada bajo criterios de autoridad, o bajo supuestos de autorresponsabilidad compartida de sus miembros, o construida sobre un sentimiento fuerte de mutua pertenencia, etc., este simple hecho está interviniendo en la conducta, incorporando un modo de ser, estableciendo unas pautas y modelos de comportamiento que ingresan directamente a formar parte de la experiencia individual. Las experiencias acumuladas a través de otras instituciones, de la interacción grupal o de la organización escolar afianzarán o corregirán en parte aquella experiencia primaria. Pero ésta es ya inevitablemente el horizonte y el campo sobre el que las otras van emergiendo o contra la que se van expresando. Esta influencia, decimos, no es deliberada ni conscientemente planificada. Sucede únicamente y se deriva de la propia interacción. La otra dimensión desde la que la comunidad o el grupo, la escuela o el estado toman parte en la actividad y desempeñan funciones educativas es aquella en la que aparecen propuestas consciente y reflexivamente planteadas, directa y en sí mismas dirigidas al establecimiento de un determinado modo de ser. Estas acciones directas se producen en todas las formas de comunidad y en todas las organizaciones grupales. Para algunas instituciones, para el estado y para la escuela, la planificación, el ordenamiento consciente, deliberado, reflexivo y crítico, es un requisito esencial y una propiedad necesaria de su propia naturaleza funcional. Es la razón de ser de su presencia social y humana.

Los mayores problemas educativos surgen cuando se producen incongruencias estructurales entre los distintos órdenes comunitarios, entre las planificaciones institucionales o entre la planificación y la estructura. Porque, entonces, el individuo se encuentra dividido entre demandas que pueden llegar a ser contradictorias. La comunidad inmediata, los grupos primarios, la escuela y el estado tienen que armonizar entre sí, sin que una suprima a la otra, toda su organización y todas sus demandas programáticas.

Si los sociólogos han denunciado la progresiva desaparición de la "comunidad inmediata", de los grupos primarios, y su constante absorción por las "organizaciones societarias", secundarias, esto representaría un problema educativo de magnitudes impredecibles. Porque sin su amparo es muy difícil lograr un equilibrio estable de la personalidad. Homans llegó a afirmar que "si hay una verdad establecida por la psicología moderna, es la de que un individuo aislado está enfermo. Tiene la mente enferma: Exbibirá desórdenes de conducta, emoción y pensamiento; además, como lo enseña la medicina psicosomática, quizá tenga enfermo su cuerpo". Cuando habla Homans de aislamiento se está refiriendo, sobre todo, a la carencia de un ámbito "comunitario" propiamente tal, de esa forma comunitaria que constituye la familia, el grupo de amigos o las "relaciones de vecindad". Ni la escuela ni el estado pueden suplir a la familia. Sus estructuras y sus funciones son distintas. La escuela, como lugar de formación integral y centro especializado de enseñanza, necesita su concurso, participación y ayuda para desempeñar su labor educativa plena y satisfactoriamente. 


\section{FAMILIAS Y CASAS}

Las comunidades inmediatas, los grupos primarios, las familias, no pueden ser entendidas sin sus casas, sus viviendas y domicilios, sus lugares de encuentro y aposentamiento. Las casas son la forma material de su concreción en el espacio y en el tiempo. La historia de la familia y de su papel social se puede seguir a través del que han desempeñado sus casas y de las modalidades que han ido adquiriendo (Echeverría: 1995).

La casa es un punto, un lugar donde el ser humano se refugia o simplemente se concentra con los suyos. Es un centro en el que se hacen converger los afanes y los caminos de la vida. Es lo que prolonga el cuerpo propio hacia las cosas que llegan a ser más rigurosamente propias. Es una forma material del mí mismo que, junto a mis pertenencias psíquicas, constituirá el microcosmos directo de mi singularidad. Es el crisol de la primera individualidad y de la inicial socialización. Es señal de permanencia y duración.

Charles Abrams y J.P. Dean han visto las casas, los hogares, como una mezcla de elementos complejos, no sólo por lo que realmente son, sino por lo que de hecho pueden ser.

1. La casa es una posesión, algo que se tiene y en lo que se invierte el "ego personal y familiar.. Una parte importante de los ingresos conseguidos se destinan a su adquisición y a su dotación.

2. Es una expresión de los gustos y de las características personales.

3. Puede facilitar una vida propia y el desarrollo de actividades y prácticas intimas.

4. El hogar es el signo de la vida privada. Puede ser el ámbito de la espontaneidad y el espacio para la libre expresión de los sentimientos.

5. Pueden ser los hogares los "bastiones de la vida emocional" frente a la dureza de un "mundo demasiado grande, demasiado rápido y demasiado complicado" donde los hombres y las mujeres tienen que competir frenéticamente los unos contra los otros.

6. Son, o pueden ser, el centro de interacción con los conocidos, con los amigos y con los suyos, separados de los otros, los extraños, el resto del mundo. Con frecuencia están rodeadas de recuerdos, de vivencias anteriores, de las fantasías y ambiciones de futuro, de todo aquello que se reviste de una significación profunda y única para sus moradores. (Abrams y Dean: 1972, 256).

Las casas se pueblan de resonancias en las que todos sus miembros se encuentran comprometidos. Son voces, sonidos y silencios, que sólo prosperan en el interior de sus tabiques. Sometidas al aire exterior se agostan y mueren. 


\section{ACTIVIDADES Y FUNCIONES}

La nota más reiterada de lo que sucede en el interior de las comunidades inmediatas, de los grupos primarios, de las familias y de sus casas, apunta hacia el componente emocional de la vida humana. Es una dimensión quebradiza, fácilmente alterable, sometida a flujos incontenibles, más allá y más acá de la razón científica, de la razón formal, de la razón técnica. No se controla ni se desencadena con la misma facilidad con la que manejamos el interruptor de la luz, o el arranque del automóvil.

A las comunidades inmediatas y a los grupos pertenece, decía Tönnies, todo lo que es confiable, íntimo, que sólo vive en conjunto. Y Cooley consideraba que los grupos primarios se "caracterizaban por una asociación y cooperación íntimas y directas. Desde el punto de vista psicológico, el resultado de la asociación íntima es una cierta fusión de individualidades en un todo común, de manera que la personalidad de cada miembro, por lo menos en muchos sentidos, está constituida por la vida y por la finalidad comunes del grupo... Implica aquel tipo de simpatía y de identificación mutua expresado por el término "nosotros" (Cooley: 1962, 23).

Las relaciones que sólo viven en conjunto significan algo más que el mutuo requerimiento de las partes. Esto, en general, sucede con cualquier forma asociativa. Para que haya una relación tienen que existir, al menos, dos elementos que se conectan entre sí. Lo que ocurre es que, en la mayor parte de las formas relacionales, los elementos son fácilmente intercambiables. Actores y espectadores se necesitan. Y podemos afirmar que no hay actores sin espectadores. Pero cualquiera puede brindar su entrada a un espectáculo, delegar en otra persona que lo sustituya, sin que esta alteración modifique el espectáculo. La suplencia, o la posibilidad de suplencia, es la marca de la mayor parte de nuestras relaciones sociales. No ocurre así con las relaciones comunitarias y con los grupos primarios. Cada una de las partes se perfila en cuanto integrada en el todo, como una unidad superior, cuyo formato determina la propia singularidad y la personalidad diferenciada de cada uno. No se sustituye la paternidad biológica ni la paternidad putativa con la misma facilidad con la que se intercambia una entrada para el cine. Estas relaciones comunitarias ponen en juego la realidad subjetiva del ser humano. Por eso, una comunidad inmediata, un grupo primario, una familia, no se disuelve nunca sin tensión, sin desgarro, sin tragedia. Cuando en esas relaciones se instituye el intercambio, la comunidad inmediata o el grupo primario desaparecen en cuanto configuraciones humanas.

No tiene sentido intervenir en las partes aisladamente. Sólo es posible actuar sobre una unidad teniendo en cuenta al conjunto.

Hay otra razón que dificulta la sustitución, que hace de los intercambios en este orden de cosas una tragedia. Es cierto que estas relaciones sólo viven en la comunidad como conjunto; pero, como se ha afirmado repetidamente, aunque parezca paradójico, esta comunidad, que se construye siendo un elemento de identificación, requiere de sus miembros la singularidad y la individualidad. Ello hace 
de la educación ocurrida en su seno algo totalmente distinto de la que puede suceder en la escuela. Así lo interpretó con toda nitidez Niklas Luhman: "La educación en el sistema de interacción enseñanza se diferencia esencialmente de la educación en las familias; y ello porque la observación y comprensión se dirigen de otro modo. En las familias, todas las diferencias son individuales. Así son en todo caso percibidas y practicadas. Se remontan al hecho de que Hans no es Grete y papá no es mamá. La persona se individualiza como referencia respecto a los otros. Es algo que no hace falta decir, que está siempre establecido. Por ello, las diferencias entre las personas son un principio primario de la obtención de información... En todos los acontecimientos familiares se averigua algo sobre personas a las que ya se conoce, lo que, viceversa, obliga también a las personas a dejarse disciplinar por su ser-ya-conocidos, a no apartarse demasiado de su línea. La familia socializa también sin educación intencionada, porque siempre se da por entendida" (Luhmann, 1996, págs. 117, 118).

En el interior de esta realidad subjetivo-material, compuesta por relaciones comunitarias, grupales y domésticas, se desarrollan un conjunto de actividades que formarán los cimientos de la vida. Son, en gran parte, las que Echeverría adscribía a los hogares y a las conductas que en ellos tienen lugar:

1. Antes de nada, en estos ámbitos se inician los primeros pasos en el uso de la razón. No se trata de que el ser humano carezca de disposiciones para la racionalidad, sino de que el primer uso y ejercicio, los primeros balbuceos de la razón acontecen en el seno de las familias. Y sin esa originaria manifestación y modelamiento quizá nunca se consiga un adecuado desenvolvimiento ulterior.

Con el aprendizaje de la lengua materna se emprende el largo camino de la razón, de la individualización y de la socialización básica.

2. En las casas se reconforta el ánimo, "se reconstituyen las personas". El cansancio, la enfermedad y el dolor tienen ahí el espacio adecuado de sus primeros auxilios. "Por mucho que se haya desarrollado la sanidad pública, generando las casas de salud, que algo tienen que ver con la hospitalidad y lo doméstico, lo cierto es que se sigue considerando digno que una persona muera en su propia casa, rodeada de los suyos. El cansancio, la debilidad, la agonía y la muerte se plasman en las casas". (Echeverría: 1995, 49 y ss.).

3. La identidad personal tiene aquí sus primeras adscripciones. El nombre propio y el lugar de nacimiento acompañarán al individuo durante el resto de sus días como señales básicas de identificación.

4. Las representaciones y los actos de uno mismo frente a otros individuos, las alianzas y los pactos de convivencia, el amor y el odio, el llanto y la alegría, son la corriente diaria, el pan cotidiano de los hogares, las familias, de lo que con más propiedad pertenece a la comunidad inmediata.

5. La memoria colectiva y la memoria personal profunda e íntima se hermanan en los recintos del hogar. Las experiencias compartidas, las creencias, 
los objetos que después se transmitirán a otras generaciones forman parte del equipaje con el que vamos siendo nosotros mismos.

6. Las casas son el símbolo de la propiedad privada. La familia, la comunidad inmediata, representan, sin más, la privaticidad, lo privado (Echeverría: 1995, 54).

7. La comunidad inmediata, el grupo primario y el hogar son el fundamento de la vida afectiva. La inteligencia emocional, que Daniel Goleman ha descrito, encuentra ahí sus raíces más profundas.

La historia ha sometido a cada uno de los aspectos mencionados a los mil avatares por los que ha pasado el hombre. Y, hoy, podemos interpretar el mundo en el que nos encontramos a través de las vicisitudes por las que atraviesan esos distintos rasgos. Gorz, por ejemplo, contrapone la vida privada a la vida profesional. Son, dice, conductas radicalmente distintas, contrapuestas. La profesionalización creciente, dominante, puede llevar a formas de privacidad compulsiva, a formas reductivas, que eliminen cualquier otra consideración de la vida comunitaria. La educación social, en este caso, tendrá que desempeñar el papel de un recurso para restaurar el equilibrio, reconstruir un orden humano. Para intervenir en estos ámbitos no es suficiente con el conocimiento de los tipos ideales, de las formas puras. Será preciso interpretar las condiciones materiales, prácticas y culturales del momento en el que nos encontramos. De todas formas, el ejercicio sobre los tipos ideales no es inútil. Sirve para marcar el horizonte hacia donde deberían volver muchas de las turbulencias desatadas sobre la superficie de la tierra.

Ninguna escuela podrá suplir nunca las carencias profundas que se produzcan en el ámbito de las comunidades inmediatas. Ningún estado, ningún gobierno podrá, mediante distintas transferencias públicas, solucionar las deficiencias que allí se generen. El remedio sólo se conseguirá facilitando el círculo de su existencia y fomentando las buenas relaciones y una conexión armónica con el resto de las instituciones humanas.

\section{CONCLUSIÓN}

Las comunidades inmediatas, los grupos primarios, los hogares y las casas representan un mundo al lado de otros mundos. Por ellos circula una parte fundamental de nuestra existencia. En ellos se depositan algunos de nuestros sueños más secretos y personales. En el otro lado se encuentran los grupos secundarios, las relaciones profesionales, los intercambios mercantiles, los sistemas de producción, los núcleos de poder, los espacios públicos, los lugares de paso, los recintos urbanos, etc., etc. Estos últimos ámbitos están regidos por relaciones formales, por relaciones morales y por relaciones jurídicas de muy diversa índole. Conviene señalar que las relaciones morales se entienden aquí, aunque es de todos sabido los distintos sentidos históricos que han ido adquiriendo, como costumbres y normas que pertenecen a grupos amplios de personas y son la base de las relaciones interpersonales de 
orden social. Los primeros recintos que mencionábamos, sin embargo, son aquellos a los que corresponde lo íntimo, lo personal, lo confiable, lo privado, los sentimientos profundos de pertenencia, de afectividad y de mutua complementariedad. Éstos son, por excelencia, el reino donde brotan las primeras experiencias de lo preferible y de lo despreciable, es decir, las primeras relaciones de valor propiamente dicho, las relaciones éticas. Ninguna educación axiológica fundamental será posible sin tenerlo en cuenta y sin reproducir las mejores condiciones de aquellos espacios y de aquella convivencia directa e inmediata, equilibrada, congruente y acorde con las necesidades básicas de la especie en las que los humanos, desde siempre, se han despertado y se continúan despertando al mundo y a la vida.

\section{BIBLIOGRAFÍA}

ABRAMS, CH. y DEAN, J.P. (1972) La vivienda y la familia, en VV.AA.: La familia. Barcelona: Península, 247-274.

ANZIEU, D. y MARTIN, J. (1971) La dinámica de los grupos pequeños. Buenos Aires: Kapelusz. ARENDT, H. (1961) La condition de l'bomme moderne. París: Calmann-Lévy.

ARDOINO, J. (1967) El grupo de diagnóstico, instrumento de formación. Madrid: Rialp.

ARIES, PH. Y DUBY, G. (1989) Historia de la vida privada. 5 vols. Madrid: Taurus.

BANKS, O. (1983) Aspectos sociológicos de la educación. Madrid: Narcea.

BANY, M. y JOHNSON, L.V. (1970) La dinámica de grupo en la educación. Madrid: Aguilar. BAUDRILLARD, J. (1984) Cultura y simulacro. Barcelona: Kairós.

BEAL, M.G. Y OTROS (1964) Condición y acción dinámica del grupo. Buenos Aires: Kapelusz. BENEDICT, R. (1971) El bombre y la cultura. Investigación sobre los origenes de la civilización contemporánea. Barcelona: Edhasa.

BION, W.R. (1963) Experiencias en grupos. Buenos Aires: Paidós.

BURGUIERE, A. Y OTROS (1988) Historia de la familia. 2 vols. Madrid: Alianza.

CAMPO, S. DEL Y NAVARRO, M. (1985) Análisis sociológico de la familia española. Madrid: Ariel. CAVALLI-SFORZA, L. Y F. (1994) Quiénes somos. Historia de la diversidad bumana. Barcelona: Crítica.

CIRIGLIANO, G.F.J. y VILLAVERDE, A. (1970) Dinámica de grupos y educación. Buenos Aires: Humanitas.

COOLEY, (1962) Social Organization. Nueva York: Schocken.

COLOMA, J. (1988) La familia actual, como grupo primario y como agencia de socialización, en Escritos del Vedat (Valencia), V. 18, pp. 341-372.

DELGADO, M. (1999). El animal público. Hacia una antropología de los espacios urbanos. Barcelona: Anagrama.

DICHTER, E. (1968) Las motivaciones del consumidor. Buenos Aires: Sudamericana.

ECHEVERRÍA, J. (1995) Cosmopolitas domésticos. Barcelona: Anagrama.

FREYER, H. (1973) Introducción a la sociología. Madrid: Aguilar.

GORZ, A. (1995) Metamorfosis del trabajo. Madrid: Sistema.

GUBERN, R. (1987) El simio informatizado. Madrid: Fundeso.

HABERMAS, J. (1981) Historia y crítica de la opinión pública. Barcelona: Gustavo Gili.

HARRIS, C.C. (1986) Familia y sociedad industrial. Barcelona: Península.

HOMANS, G.C. (1970) El grupo bumano. Buenos Aires: Eudeba. 
LEWIN, K. (1951) Teoría del campo en la ciencia social. Buenos Aires: Paidós.

LUHMANN, N. (1996). Teoría de la sociedad y pedagogía. Barcelona: Paidós.

LYNCH, J. Y PIMLOTT, J. (1979) Padres y profesores. Madrid: Anaya.

MAILHIOT, B. (1971) Dinámica y génesis de los grupos. Madrid: Marova.

MANNHEIM, K. (1966) Introducción a la sociología de la educación. Madrid: Revista de Derecho Privado.

MERTON, R.K. (1972) Estructura social y economía: Revisión y ampliación, en VV.AA.: La familia. Barcelona: Península.

NAISBITT, J. (1983) Macrotendencias. Diez nuevas orientaciones que están marcando nuestras vidas. Barcelona: Mitre.

PARSONS, T. (1972) La estructura social de la familia, en VV.AA.: La familia. Barcelona: Península.

POSTMAN, N. (1994) Tecnópolis. La rendición de la cultura a la tecnología. Barcelona: Círculo de Lectores.

RIVIÈRE, M. (1995) La década de la decencia. Barcelona: Anagrama.

SENNETT, R. (2000) La corrosión del carácter. Las consecuencias personales del trabajo en el nuevo capitalismo. Barcelona: Anagrama.

TÖNNIES, F. (1979) Comunidad y asociación. Barcelona: Península.

- (1987) Principios de sociología. México: F. de C.E. 